\title{
Una reflexión sobre la violencia y la construcción de paz desde el teatro y el arte $^{1}$
}

\author{
Patricia Tovar ${ }^{2}$ \\ John Jay College, CUNY, Nueva York, Estados Unidos ${ }^{3}$ \\ ptovar@jjay.cuny.edu \\ Recibido: 13 de febrero de 2014 \\ Aceptado: 17 de junio de 2014 \\ Disponible en línea: 15 de marzo de 2015
}

1 Este artículo de reflexión se origina a partir de varios años de trabajo sobre el tema de la violencia y la resolución de conflictos y explora el uso del arte y del teatro como posible herramienta transformativa en la construcción de paz. Se agradece la colaboracion del John Jay College, del Grupo de Títeres el Guiño el Guiñol, de su director Camilo Cuervo, de Lucila Chica y de la AECID, Agencia Española de Cooperacion, en la elaboracion de este articulo.

2 PhD en Antropología Cultural

3 Profesora titular en el Departamento de Antropología de John Jay College of Criminal Justice 


\title{
Una reflexión sobre la violencia y la construcción de paz desde el teatro y el arte
}

\section{Resumen}

Este artículo es una invitación a pensar en el arte y el legado de la violencia y la injusticia en la historia de la humanidad y en los esfuerzos trabajados desde diferentes proyectos artísticos en la resolución de conflictos y en la promoción de la paz en el mundo. Se presentan y analizan algunas de esas experiencias y se examina cómo han sido aplicadas por diferentes disciplinas para resolver o avanzar sobre algunos de los problemas que aquejan a la sociedad. Es también importante pensar en el uso del arte, del teatro y de la creatividad como estrategia metodológica y como un ejercicio de investigación participativa que permita la investigación transformativa en el campo de la violencia y el trabajo en grupo desde las comunidades afectadas.

Palabras clave: violencia; arte; teatro; performatividad

\section{A reflection on violence and peacebuilding from theater and art}

\begin{abstract}
This paper is an invitation to think about art and the legacy of violence and injustice in the history of mankind and the efforts from different artistic projects on conflict resolution and the promotion of peace in the world. Some of these experiences are presented and analyzed and it is examined how they have been applied by different disciplines to solve or make progress on some of the problems society faces. It is also important to think about the use of art, theater and creativity as a methodological strategy and as an exercise of participatory research that allows transformative research in the field of violence and teamwork from the affected communities.
\end{abstract}

Keywords: violence; art; theater; performativity

\section{Reflexão sobre a violência e a construção de paz desde o teatro e a arte Resumo}

Este artigo é um convite para pensar na arte e o legado da violência e a injustiça na história da humanidade e nos esforços trabalhados desde diferentes projetos artísticos na resolução de conflitos e na promoção da paz no mundo. Apresentam-se e analisam-se algumas dessas experiências e examina-se como foram aplicadas por diferentes disciplinas para resolver ou avançar sobre alguns dos problemas que afligem à sociedade. Também é importante pensar no uso da arte, do teatro e da criatividade como estratégia metodológica e como exercício de pesquisa participativa que permita a pesquisa transformativa no campo da violência e o trabalho em grupo desde as comunidades afetadas.

Palavras-chave: violência; arte; teatro; performatividade 


\section{¿Cómo se puede promover la paz a través del arte?}

En este artículo se hace una reflexión sobre cómo el arte, el teatro, el ritual y otras tradiciones culturales han servido para crear puentes, cerrar diferencias en situaciones de conflicto, reconciliar o reparar comunidades divididas por la violencia y pensar en futuros posibles en paz. Muchos de los casos que se presentan y analizan han servido como lecciones creativas que pueden ser aplicadas en espacios callejeros, escuelas, poblaciones, e inclusive en centros de detención. Se trata de caracterizar y resaltar algunos ejemplos que han sido usados creativamente para transformar situaciones de abuso de poder, agresión y desigualdad.

El poder del arte para promover la paz reside en su carácter emotivo. Cuando se habla de arte se hace referencia en este caso particular, a las artes en general, a la música, el teatro, la poesía, la literatura, la danza, y las 'artes visuales' como la pintura, la escultura y la fotografia. Todas estas expresiones contribuyen de diferentes maneras. Veamos la fotografia, por ejemplo. Susan Sontang (1990), en su famoso ensayo sobre el tema, la describe como una evidencia de algo que oímos pero dudamos y que nos ayuda a probar la existencia de un evento violento. La cámara incrimina, sirve de prueba en la corte para castigar culpables de crímenes. La cámara también captura e interpreta la realidad, puede mostrar la violencia o la miseria de manera estética removiendo su esencia.

Este análisis se centra principalmente en el teatro, el drama y la comedia, donde se hacen trabajos colectivos de actuación y de representación como herramientas de resistencia y de transformación y se resalta el tema de la paz y el mensaje de la no-violencia. Muchas expresiones artísticas han sido explícitamente producidas en respuesta a la guerra, mostrando la crueldad, la sangre, el trauma y los horrores que deja a su paso. El arte ha dedicado un menor esfuerzo en promover explícitamente la paz. Por eso hablar de arte que construye paz es en cierta manera más difícil ¿Cómo se podría definir este tipo de arte y las obras que cabrian dentro de este grupo? ¿Qué tipo de sensibilidades deben expresarse? ¿Qué se está comunicando? ¿A qué emociones 
se puede apelar? ¿Qué compromisos se deben tener? ¿Cómo puede responderse de manera efectiva a esto? El arte de la guerra nos muestra el horror de lo que pasó. El arte de la paz nos hace vislumbrar un futuro diferente.

Antes de entrar en detalle en este análisis es importante entender cuál es la función del arte en la sociedad, siguiendo a Bickhart y Benn (2004), ha sido una herramienta invaluable que nos ha llegado desde la prehistoria y nos habla sobre la sociedad que lo produjo. El arte emerge y refleja el contexto social, político, económico, histórico y religioso del grupo en el que surge. Por eso el arte muchas veces ha sido controlado por los poderosos y los vencedores, pues permite reforzar el poderío e inspirar grandeza, como las estatuas, los obeliscos y los arcos del triunfo; pero a la vez es una apropiación colectiva, cultural e incluso religiosa llena de muchos significados, que sirve para educar y para expresar emociones.

\section{¿Pueden el teatro y el arte en general ayudar a disminuir la violencia?}

Aunque los conflictos y las formas de resolverlos en las diferentes sociedades han sido documentados desde tiempos remotos en la historia de la humanidad, solo recientemente se ha creado una disciplina académica que trata de estudiar cómo minimizar la capacidad de destrucción de la violencia y de trabajar hacia la construcción de paz. Dentro de este se ofrecen propuestas, teorias y herramientas con miras a prevenir y resolver un problema, ayudando a las partes involucradas al entendimiento, la tolerancia, mejorar la comunicación y en últimas a resolver sus diferencias. En muchas universidades ya se ofrecen programas de doctorado en Resolución de Conflictos o Estudios para la Paz, como áreas independientes de especialización con herramientas teóricas y metodológicas especificas, en lo que antes se llamaba solo ciencias sociales.

En Colombia aún tenemos que trabajar mucho en esa dirección. Aunque se resaltan los esfuerzos locales como los del oriente antioqueño, como por ejemplo la Fundación Amory los Tejedores de la Memoria, 
por nombrar apenas unos casos en las regiones. A pesar de los recientes trabajos sobre memoria en diferentes zonas del país, nos cuesta trabajo reconocer y nombrar la violencia, admitir que hay víctimas, aceptar el sufrimiento y las culpas, pedir perdón, resarcir y castigar. Para dar sentido a todo esto es necesario trabajar aspectos concretos y simbólicos, narrando y recuperando la memoria y dando coherencia a nuestra historia. Es allí en ese nivel simbólico donde nuestro sentido de lugar y de identidad se forja, en la vida diaria. Es precisamente en ese espacio donde la creatividad juega un papel fundamental para el entendimiento propio y el de los demás, para borrar las diferencias que nos dividen, para tocar los profundos componentes de nuestros conflictos y reconocer nuestra parte de responsabilidad; para saber dónde nos duele y por qué, para revisar nuestros cuerpos y ver dónde reside el miedo y el dolor y para buscar ahí mismo los recursos que nos van a permitir sanar y crear un mejor país.

La pregunta que guía este trabajo es una que ya se ha planteado en muchos escenarios, como ya lo ha expuesto John Paul Lederach en su texto: La imaginación moral (2008), es ¿cómo trascendemos el círculo de violencia que hemos vivido en el país por muchas generaciones? Para esto se ofrece una propuesta desde el arte. Se trata no solo de entender las causas de la violencia, sino de creer en la posibilidad de un cambio a través de la creatividad para poder escapar de ese ciclo. Se trata de vislumbrar un mundo más allá del conflicto y la desigualdad, donde también podamos convivir con nuestros enemigos.

Como ya lo dijo el mismo Lederach y lo han dicho muchos otros, el arte permite crear, movilizar, construir, soñar, curar, transformar, descubrir, reconciliar y establecer nuevas relaciones. Muchas obras de arte, como el teatro y la literatura, se articulan alrededor de la resolución de un conflicto. De ahí la inmortalidad de obras que nos muestran cómo los conflictos son a su vez poderosos dramas. Ejemplos como Romeo y Julieta, Ricardo Tercero, el Rey Lear, el Mercader de Venecia, por no ir más lejos y mencionar apenas un autor. Shakespeare nos sigue confrontando con todo el rango de las pasiones humanas, el crimen y la injusticia. 
El arte es un vehículo eficaz para expresar las diferencias políticas y sociales y las tensiones y la rabia desencadenada por los conflictos, a la vez que permite movilizar comunidades. Por esta razón, expresiones culturales como los desfiles, carnavales, procesiones, prácticas religiosas, monumentos, indumentarias y lenguajes tienen fuertes cargas emocionales y políticas y se convierten fácilmente en elementos que crean unidad. Por esa misma razón permiten cerrar las diferencias entre oponentes. Además de esto, todas las culturas contienen símbolos e imágenes de paz, elementos comunes y arquetipos universales que permiten sanar, reconstruir y reconciliar. En otras palabras el arte y la cultura permiten cambiar formas de actuar y formas de relacionarse para que fluyan en una dirección positiva.

¿Cuáles son entonces las diferentes propuestas que el arte puede ofrecer para construir paz? Esta pregunta puede analizarse desde diferentes ángulos y puede tener una respuesta diferente según el grupo que la plantee, ya sean los activistas que trabajan a favor de los derechos humanos, los conciliadores que están tratando de hacer dialogar a los grupos en conflicto, los que trabajan con desmovilizados, los grupos religiosos intentando la reconciliación, las organizaciones no gubernamentales que están capacitando constructores de paz, las entidades de ayuda humanitaria, o las entidades de gobierno que están creando políticas públicas.

Hay organizaciones que prefieren trabajar directamente donde están los actores de la violencia, ir directamente a los barrios marginales, buscar a los perpetradores y a las victimas de la violencia y hacer que cuenten sus historias a través del arte. Hay muchos ejemplos de este tipo de trabajo. Por ejemplo Círculos Culturales ofrece un proyecto de fototerapia a niñas de Caracas. El Guiño del Guiñol llevó títeres y talleres de arte a las escuelas del sur de Bogotá con el fin de buscar alternativas creativas a la violencia. El denominador común de todas estas organizaciones es que se debe hacer un trabajo integrado y colectivo, creando procesos de cambio social desde la comunidad, generando estrategias de resolución de conflictos.

Por supuesto que hay muchos argumentos sobre la necesidad de procesos de paz formales para acabar con la violencia y de esta manera 
propiciar la reconciliación para que se pueda construir la paz. Pero es mejor comenzar a trabajar en esa dirección y no quedarse esperando a que eso ocurra y menos en el caso de un país como Colombia, donde la violencia ha sido un mal crónico.

Se podría afirmar que el arte permite anticiparse a los procesos de paz formales y estar presente en cada uno de los momentos de construcción de una sociedad postconflicto. Esto se ve en los murales y los grafitis que llenan las paredes. $\mathrm{El}$ arte junto con otros elementos de la cultura puede utilizarse para enseñar a reconocer culpas, aprender a pedir disculpas, reparar y perdonar, pasos necesarios en una reconciliación donde las partes afectadas van a continuar conviviendo juntas.

El arte y su puesta en escena es más que simple entretenimiento. Es más que un dispositivo didáctico o un mecanismo que propicia la catarsis. Es verdaderamente una ocasión para que una cultura y una sociedad se definan a sí mismas, dramaticen su historia y su mitologia colectiva, nos propongan desafios, se nos presenten alternativas y modos de ver el mundo diferente y eventualmente, nos reafirmemos o cambiemos maneras de ser que nos causan ansiedad e inconformidad.

Como vemos, el arte es más que una herramienta poderosa, pero se trata de ir más allá y trabajar sus verdaderos alcances en situaciones especificas, integrándola a una pedagogía permanente de construcción de paz. La acción ritual y simbólica que el arte propicia es muy útil en los procesos de paz por varias razones: En primer lugar permite expresar y nombrar cosas cuando no se pueden hacer de manera directa. En segundo lugar, las palabras de disculpa y de perdón pueden sonar vacías y poco sinceras si no van acompañadas de actos significativos. Y en tercer lugar, mientras que las palabras son más cognitivas, los actos simbólicos nos llegan a nuestra inteligencia afectiva y nos tocan los sentidos de maneras diferentes.

Las intervenciones para construir la paz y la reconciliación deberian contemplar más una dimensión artística que permita desde la infancia y la escuela temprana ofrecer unos mecanismos emocionales y cognitivos que disminuyan la agresión y ayuden a resolver los conflictos y los problemas sin violencia, rompiendo el esquema que se repite de 
generación en generación. El arte y sus aspectos simbólicos son muchas veces dejados de lado cuando se trabaja en la resolución de conflictos y en la construcción de paz. Los actores que participan en este esfuerzo deben coreografiar una serie de movimientos, atraer a la gente a un proceso visual donde los sentidos, las emociones y las pasiones se pongan en juego. Estas intervenciones no se deben limitar a la escuela sino que deben incluir a toda la comunidad, transformando también el entorno social. El arte es liberador y permite dar voz, ventilar y llamar la atención a cosas que no se pueden expresar de otra manera.

Hablar de ritual significa hablar de actos simbólicos formales o informales realizados en espacios no cotidianos, que al ser ritualizados pueden adquirir un carácter sagrado, más permanente, actos en los que se trata de dar forma y transformar algunos aspectos de la identidad, la visión del mundo, o las relaciones.

En este contexto vale la pena utilizar el concepto de Social Drama que Víctor Turner ${ }^{4}$ elabora a partir del trabajo que Van Gennep (1960) hace de los ritos de paso y que sirve para entender el efecto que este drama tiene en un escenario y cómo este a su vez ayuda a configurar rupturas sociales, crisis, cismas, inconformidades o desavenencias y por tanto permitir el ofrecimiento de reparaciones alternativas. El drama que se lleva a cabo no existe sin una audiencia. Quien observa el drama tiene el papel de percibir los significados ocultos, los principios estructurales, y de pensar en soluciones a los conflictos que allí se manifiestan, por eso el origen de la palabra teatro viene del griego y significa "lugar para contemplar." Este espacio de representación junta lo natural con lo cultural de diversas maneras y puede llamarse ritual, teatro, pintura, música, peregrinación, carnaval, cine o cualquier nombre que se le dé a las nuevas producciones emergentes. Ejemplos de estos dramas sociales aparecen en todas las culturas en pequeña o en gran escala.

El ritual permite reinterpretar y deconstruir símbolos, dar nuevas lecturas con el fin de transformar significados. Un ejemplo es el

\footnotetext{
4 Este concepto lo trabaja Turner en varias de sus obras más importantes entre ellas, La selva de símbolos (1990) y El Proceso Ritual (1988).
} 
trabajo de la artista y 'performancera', como se ha llamado a la mexicana Astrid Hadad ${ }^{5}$, que reinterpreta poderosos símbolos mexicanos como la Virgen de Guadalupe. Ella misma se convierte en escenario y en altar, de manera que cuestiona a la virgen como el paradigma de la mujer mexicana para hacerla salir de su marco tradicional, vestirla como una mujer moderna, irreverente y atrevida que toma las riendas de su propia vida.

Esta reinterpretación de los símbolos hace parte fundamental del trabajo con jóvenes. Las posibilidades del arte son enormes en relación a la transformación de los ritos de iniciación, en particular los masculinos, que construyen una identidad varonil basada en una cultura de la agresión y la violencia y que se redefinen en espacios urbanos en la formación de barras bravas, pandillas, sicarios y otros grupos al margen de la sociedad y de la ley.

La guerra y los conflictos, así como el fútbol y otros espectáculos de masas donde se genera violencia, son a su vez un drama social que ocurre en un escenario. Hay muchos paralelos entre actores de paz y actores armados. Hay discursos, parlamentos, textos y subtextos, vestuarios, maquillajes, música, lenguajes narrativos, escenografias, símbolos y mundos imaginarios y sobre todo, la relación entre apariencia, verdad y realidad que se confunde y se torna muy problemática. Este drama social es la materia prima que se debe trabajar para los escenarios de paz.

Cuando Erving Goffman (1993) analiza la interacción social y nos habla de la dramaturgia de la vida cotidiana, utiliza la metáfora del teatro como herramienta para examinar el comportamiento de las personas en una realidad determinada. Las personas son actores que actúan en interacciones diarias, en diversas representaciones públicas y otras privadas, que no se hacen a los demás, viviendo una doble vida con un trasfondo oculto entre bastidores. De ahí, Goffman pasa a su análisis sobre el 'estigma' o el deterioro de la imagen social, las marcas en el cuerpo, en el carácter individual, en el grupo. La herencia de haber sido desplazado, de haber pertenecido a un grupo

\footnotetext{
Para mayor información se puede consultar su página web oficial: http://www.astridhadad.com/
} 
armado, a la familia de algún criminal notorio, es casi una sustancia que contamina, despersonaliza, produce miedo y ansiedad y se transmite, de generación en generación. Es una marca viva, ya sea visible o invisible que deshumaniza, justifica genocidios, produce rechazos sociales; lo que nos confronta con la ambivalencia y la necesidad de resolver el problema del individuo estigmatizado, que puede tener también el nombre de paramilitar o guerrillero, que lleva marcas impuestas que deben minimizarse en una situación de post-conflicto.

A continuación se presentan ejemplos y se analizan algunas expresiones artísticas que se han utilizado de manera exitosa en diferentes contextos y sociedades

\section{Los posibles usos del humor}

Quienes trabajan en resolución de conflictos deben aprender a entender los chistes lanzados entre oponentes y a encontrar el humor dentro de estos (William, 2001). Así se incrementa el diálogo y la tolerancia y se interviene constructivamente. Sin embargo, hay que tener cuidado con la delgada línea entre el chiste y el insulto, pues los hay de muchas clases y estos pueden aumentar el conflicto o ventilarlo en ciertos contextos. El intercambio ritual de agresiones verbales, sin pasar necesariamente a las fisicas ha existido en muchas culturas y cumple el papel de un ejercicio de deshago, pero a la vez, de control social y hasta de exclusión.

El humor, en cualquiera de sus formas, ya sea el chiste, la comedia, la caricatura, entre otras de sus expresiones, es un ejercicio de entendimiento, una confusión planeada con el fin de ser clarificada por la audiencia. Tanto los bufones de las cortes europeas como los payasos sagrados de los grupos indígenas de Norte América han cumplido la función de expresar lo que no se puede decir, pensándose incluso que se encuentran en contacto con realidades alternativas o más elevadas (Babcock, 1984). Es esta una aceptación del discurso de transgresión, del anti-lenguaje, de la norma y del poder. 
En muchas ocasiones el humor negro se convierte en una reacción humana, una manera de discernir o de asimilar situaciones extremas o incomprensibles. Es también una forma de responder al miedo y de celebrar que estamos vivos. Por ejemplo, tragedias como la caída de las Torres Gemelas en Nueva York, generó en pocos días una enorme cantidad de chistes cínicos y retorcidos que nadie se explicaba de donde salian. El humor es una importante herramienta que hace parte de los conflictos y que por tanto, se debe utilizar en su resolución y en la construcción de paz. El humor ayuda a canalizar emociones, a socializar y a humanizar, a decir verdades y a protestar ante situaciones injustas.

Se puede decir que la burla permite revelar lo serio dentro de lo absurdo y es un remedio infalible contra el miedo, pero más que eso, nos abre una ventana a la psiquis y a los valores de una cultura. Volver a reír después de un trauma nos hace redefinir y tal vez aceptar la vida, pues la risa nos libera de los miedos, las sujeciones de la cultura, de las normas y del poder.

Los chistes necesitan una audiencia y la proliferación de estos une a la gente, provoca solidaridad, enfatizando que no se está viviendo solo en ese momento, si no que hay una colectividad de personas reaccionando en conjunto. El humor nos da la capacidad de adaptación, de aceptación de lo inaceptable. Nos recuerda que somos humanos frente a lo inhumano. Algunos humoristas conjugan esa ansiedad colectiva en la caricatura, o dicen verdades que los noticieros y los gobernantes ocultan y que nadie más puede decir, logrando así evadir la censura, como en el caso de Tola y Maruja, y de muchos otros humoristas colombianos. El poder del chiste radica en que una vez que se lanza al viento o al mundo virtual, es imposible erradicarlo.

El chiste ridiculiza a los que se exceden en el poder. De hecho, en algún momento dado, quienes caricaturizan a otros se pueden volver subversivos y peligrosos para quienes están en el poder o cometen crímenes, en el caso de fue Jaime Garzón, por levantar su risa acusadora y por ser el más sensato entre el grupo de bufones que gobernaban el país. Por ejemplo, en una de sus frases celebres nos dio esta perla: "Samper está dictando Cátedra Colombia en España. Me parece que es una buena venganza porque fueron como 
cinco siglos de engaño de parte de los españoles a nosotros. Ahora los estamos engañando".

Pero también una de las respuestas al trauma es la risa incontrolable, nerviosa, inapropiada. En este caso es tal vez la única reacción posible en un mundo distorsionado, donde las otras posibilidades ya no existen. Pero a la vez las respuestas 'normales' como la rabia, o el llanto en esa situación, no hubieran ayudado en nada y tal vez hubieran resultado en un aumento de la vulnerabilidad de la víctima.

Dentro del ritual y del contacto con lo sobrenatural y cerca del bufón y el payaso, se encuentra un personaje que con malicia, humor y picardia rompe también las reglas entre lo humano y lo divino y que hace parte del universo de pobladores del drama social. Es un arquetipo que se presenta en forma animal, pero que tiene características humanas y que ha servido para mediar entre mundos desiguales e injustos. Es el tío conejo, un duende, el coyote de los indígenas de Norte América, es Anansi, en África, es Loki en los países nórdicos, es el Mercurio o el Hermes de la mitología antigua. Es el tramposo, el enredador, el villano que se burla de nosotros y nos juega malas pasadas. Pero queremos mucho a este personaje, pues enreda y traba a los poderosos, pero ayuda a los desvalidos. Es el pequeño ganando al grande, no con la fuerza, sino con la astucia y la malicia. Vence las pruebas que la vida le pone en frente, sin recurrir necesariamente a la violencia, evadiendo monstruos y amenazas y recibiendo la recompensa al final y por tanto, se acerca a la audiencia con sus personajes mediadores entre lo humano, lo animal y lo divino para resolver conflictos cotidianos.

La palabra hablada como forma artística incluye un vasto repositorio de herramientas donde también reside la lirica, la poesía, el cuento, y la narrativa oral. Cercana a esto se encuentran el canto y la música, $\mathrm{El}$ enorme repertorio de cantos sagrados, lamentos, coros, letanías, sílabas repetidas, rezos, invocaciones y otras muchas expresiones, patrimonio antiguo de la humanidad, están llenos de mensajes y de dobles intenciones. El canto ayuda a articular la emoción contenida. Vienen al caso las plañideras, aquellas mujeres que eran contratadas en los velorios para poder hacer brotar el llanto de los dolientes, que no podian asumir inmediatamente la realidad de la muerte. El papel que cumplia 
la fiesta del alabado chocoano, era similar, era una catarsis y una manera de mitigar un sufrimiento histórico y el dolor, la perplejidad e impotencia por la pérdida de tantas vidas infantiles.

\section{Carnavales y cencerradas: Pugnas entre el orden y el desorden}

Otras expresiones culturales colectivas que también permiten realizar una catarsis son los carnavales. Roberto da Matta (2002) examina el famoso carnaval brasileño desde el punto de vista del problema de la transformación del mundo cotidiano en 'un mundo invertido', en sus aspectos generales y globalizantes; considerado como el paradigma de descubrirse a sí mismo. La trascendencia del carnaval y su ritualización abre preguntas relacionadas con la legitimación del orden social y la posibilidad de subvertirlo, de burla y ridiculización de los malos gobernantes, de la inversión de los géneros y las clases sociales, que podría aprovecharse en la construcción de paz. En el caso de Brasil, por ejemplo significa también la construcción de nación, de la oposición entre lo que ocurre en la casa y lo que ocurre en la calle, entre lo público y lo privado. El lugar de encuentro es la calle, que también es el escenario del conflicto político. El carnaval se convierte en la dislocación de roles sociales y de objetos, sacándolos temporalmente de sus espacios respectivos. El resultado de este desorden es que se producen escándalos, escenas, dramas y otros efectos que producen una clara conciencia de la interferencia de un lugar dentro del otro.

El momento de ritual y de euforia unifica la sociedad, pues se permite la entrada de todo el mundo, el pobre se puede vestir de rico y el hombre de mujer y todo es al contrario. La inversión que produce el carnaval permite a veces expresar, aunque sea por un solo dia, lo que verdaderamente somos o quisiéramos ser. El carnaval tiene muchos puntos de encuentro con otros actos simbólicos como las procesiones religiosas o las paradas militares e incluso las manifestaciones y protestas políticas, que ocurren en el mismo escenario y que adquieren un carácter de festival con un propósito específico.

Dentro de estas expresiones colectivas y públicas cabe también mencionar la cencerrada española, o el charivari de otras zonas europeas, 
donde a través de la fiesta, la música y la burla cruel, se protesta una situación desajustada y desigual. Un ejemplo es el matrimonio entre un anciano y una jovencita, como en el caso del famoso cuento "La cencerrada”, escrito por Blasco Ibáñez (1893). El Tío Sento, ilustre adinerado y prohombre de Benimuslim, un pueblo de Valencia, se casa con la joven Marieta, que solo aportaba al matrimonio su hermosa cara morena. Este matrimonio desnivelado no es bien recibido por los vecinos, produce una reacción de desorden callejero que se puede ver como un castigo ritual a una infracción a la norma y que incluso, como en este caso, puede resultar en tragedia, pues también se tiene el objetivo de intentar lavar una deshonra.

Como vemos, el ritual y el teatro, la liturgia y la dramaturgia se desarrollan en espacios simbólicos, diferenciados claramente de los discursos y narrativas cotidianas. Se inscriben en el mundo de la posibilidad, de la representación, del hacer-creer, de la fantasía. Ambos son artefactos de reflexión, espejos a través de los cuales la sociedad se mira, se reafirma o se critica a sí misma. Veamos entonces qué nos pueden aportar en concreto estas expresiones en los escenarios de la Noviolencia, con mayúscula y unido, como un nuevo termino de apuesta política que merece ser reconocido en su justa proporción y alcance.

\section{Algunos ejemplos de otros procesos artísticos y sus usos en la construcción de la paz}

Existen muchos ejemplos de individuos, grupos y organizaciones que utilizan el arte o procesos artísticos como el teatro, la música, las artes visuales, el cine y otros medios, para apoyar la construcción de paz en zonas de conflicto. No se trata solamente de integrar grupos previamente separados por la violencia -lo que en sí mismo puede ser un experimento muy interesante-, si no de compartir experiencias culturales similares y participar conjuntamente en proyectos creativos.

$\mathrm{El}$ arte en este caso, se manifiesta con una capacidad de impactar aspectos emocionales, psicológicos, espirituales y culturales y 
de proveer nuevas herramientas para visualizar y potenciar cambios en comportamientos agresivos. Sin embargo, es importante tener en cuenta que 'el arte' por sí solo no es una varita mágica que pueda resolver los conflictos. De hecho en algunos casos, como bien lo supo Hitler, legitima, glorifica y transmite a través de las generaciones una cultura de la violencia, como por ejemplo el uso de símbolos y colores, las danzas y canciones de guerra, los narco corridos, o los corridos prohibidos y muchos ejemplos más.

Existe también la idea del arte como terapia, que es más cercana a esta discusión y no en la psicoterapia que usa el arte como una herramienta. Es decir, no se trata de buscar procesos psíquicos, ni de descubrir material inconsciente, ni significados escondidos. Se trata más que todo de promover un sentido de identidad, de desarrollo moral y de madurez.

He llamado a esto 'el arte de los sobrevivientes', no solo de guerras, si no por ejemplo de personas en rehabilitación por traumas emocionales, desastres naturales y otros eventos que dejan profundas secuelas y producen estrés postraumático y que tiene el poder de preservar y promover la capacidad de crecimiento y autoexpresión frente a las dificultades. Se trata de ir más allá de la mera idea de recreación y de aprendizaje de nuevas habilidades. El arte como una cura para el sufrimiento emocional tiene el riesgo de convertirse en algo artificial sin sentido y $\sin$ vitalidad.

La noción de que la autoexpresión a través del arte es positiva para la gente con traumas es bastante aceptada y trabajada por muchas disciplinas. Es claro que mientras no se resuelvan las contradicciones sociales y las 'patologias' de la sociedad y de la familia que causan la violencia, habrá muchos límites en cuanto a la eficacia de estas perspectivas.

A continuación voy a exponer una serie de propuestas artísticas que se han utilizado en diferentes lugares y épocas en el esfuerzo de prevenir o confrontar la violencia y construir la paz, con el fin de tener algunas herramientas conceptuales que nos permitan ver situaciones concretas y sus resultados. Tres son los puntos para tener en cuenta 
y alrededor de los cuales giran estas experiencias de intervención: 1) expresarse y tener voz; 2) sanar y recuperarse de un trauma; y 3) permitir una reconciliación entre las partes enfrentadas o enemigas. Más adelante se vera cómo estas han sido utilizadas y han servido para confrontar la violencia y generar transformación social.

\section{Artes visuales}

Vienen a la memoria muchos exponentes de este arte que nos ha mostrado las atrocidades que deja a su paso la violencia en muchas épocas. Goya nos mostró en su magistral obra el drama de los "Fusilamientos del 3 de Mayo" durante las invasiones napoleónicas y su serie de aguafuertes "Los desastres de la guerra". Delacroix nos dejó su famosa "Libertad guiando al pueblo". Pero uno de los ejemplos más poderosos y transformativos de la época reciente ha sido el legado de Picasso denunciando las acciones bélicas y el daño que produce la guerra. Dentro de sus más reconocidos trabajos aparece el famosísimo "Guernika", cuadro que muestra el horror que dejan los bombardeos, la destrucción y la muerte de civiles que ocurrió en esta ciudad durante la Guerra Civil española. También heredamos del mismo Picasso el diseño de la paloma de la paz en 1949, símbolo que se convierte en la bandera del movimiento por la paz.

Pocos años después, la colombiana Débora Arango se consolida como una de las primeras exponentes del espanto y la brutalidad que nos deja la época de La Violencia de la década de 1950 en el país. La lista de artistas visuales que se han interesado por plasmar en el lienzo su reacción a la violencia es bastante extensa. Botero, otro de los grandes colombianos, se salió del marco de la representación nacional con sus obras para protestar sobre la crueldad de la tortura en la prisión de Abu Ghraib en Irak, por parte de soldados del ejército de los Estados Unidos.

Las artes en general, pero tal vez especialmente aquellas expresiones más visuales, están relacionadas con la memoria, específicamente en el acto de remembrar a los desaparecidos y evitar que caigan en el olvido, para conmemorar a los desaparecidos y para que no se repitan 
las cosas nefastas que han ocurrido. Las cruces de las carreteras recordando a los que murieron sin poder regresar a casa, las estrellas negras, las bicicletas blancas, nos confrontan y ayudan a reflexionar para que transitemos con mayor cuidado. La música ayuda a evocar la memoria, pero la escultura hace que la memoria se mantenga viva y se inmortalice en piedra o en otros materiales poco perecederos.

\section{Los murales}

La historia de los murales como herramientas de comunicación de trascendencia y permanencia muestra que esta es tal vez la forma más antigua de expresión pictórica, conocida por la humanidad desde la prehistoria. El mural adquiere nueva relevancia cuando se usa como propaganda de las revoluciones modernas con la intención, ya sea de protesta frente a las desigualdades sociales, las estructuras económicas y politicas opresivas e injustas. Diego Rivera y José Clemente Orozco son magníficos exponentes de este arte en México, creando una larga tradición de representar el desacuerdo con las desigualdades sociales, las estructuras económicas que beneficiaban a las élites, a la vez que realzaban la participación popular y las luchas de los indígenas, campesinos y de las clases trabajadoras que se han movilizado en ese país y muchas otras partes del mundo. Los muros han sido el foro para plasmar las injusticias sociales. Los murales son pinturas, a veces de creación colectiva, desplegadas en espacios públicos que pueden ser a veces ejecutadas sin el permiso de los dueños de los predios. El grafiti político es una derivación de este arte.

Otra clase de murales han surgido en grandes ciudades donde se recuerda y se lamentan los muertos en actos de violencia, como en el caso de obras anónimas individuales y colectivas lamentando a las víctimas de las guerras entre pandillas de jóvenes dominicanos en Nueva York.

\section{Instalaciones de arte}

Por este medio, los espacios públicos son transformados en galerías de arte. Sacar el arte de los museos permite una mirada diferente y un 
acercamiento más palpable al arte que toca y confronta a la ciudadanía en su entorno cotidiano. La artista colombiana Doris Salcedo es una gran exponente de este género, interviniendo el paisaje urbano de manera dramática como en el caso de su instalación de las sillas vacías en los muros del Palacio de Justicia en Bogotá, representando la ausencia de los magistrados, de los funcionarios y visitantes que murieron y en general de la justicia en Colombia, también al sembrar rosas en los muros exteriores del Colegio Mayor de Cundinamarca al frente de la casa donde vivía el humorista Jaime Garzón, esto nos ayudó a expresar el sentimiento colectivo de dolor por un horroroso crimen.

O lo contrario, pueden ser imágenes de espacios públicos llevadas a las galerías. Como en el caso de la artista plástica María Fernanda Cardozo y su instalación de flores plásticas que nos recuerdan el silencio y la decoración de las bóvedas de los cementerios colombianos. Este se expuso en el Museo de Arte Moderno de Nueva York.

Los murales y las instalaciones de arte nos hablan también de la necesidad de recordar y de separar de lo cotidiano los sitios donde ocurrieron horrores y tragedias. Borrar todo, tapar y esconder el dolor y la miseria humana no conduce sino a crear rencores y dejar heridas abiertas. Construir un nuevo Palacio de Justicia o unas Torres gemelas encima de los espacios afectados por la violencia, sin sanar la sociedad, es un insulto a la memoria y a la verdad. En muchos sitios, estos lugares adquieren la categoría de sagrados. Es casi un hecho universal que haya monumentos que marquen los eventos del pasado, cargados de emoción y asociados a triunfos, a derrotas o a milagros. Estos lugares son conservados y protegidos, son venerados, purificados y santificados, pues contienen las claves del pasado y del presente de un grupo.

\section{La música}

Hubo una vez un flautista que vivía en un pueblo lleno de ratas, con su música se deshizo de ellas y de nuevo arrastrando a los niños con su música, se enfrentó a los poderosos que quisieron aprovecharse de él. Aún antes hubo un pueblo que con sus trompetas y sus gritos hicieron caer los muros de una ciudad en una tierra prometida. La música 
es capaz de arrastrar multitudes, de transformar los sentimientos, de hacer brotar lágrimas, o de hacer reír. El sonido nos permite sobrevivir, nos abre ventanas de esperanza donde antes no existían y también nos recuerda que somos humanos.

No voy a hablar de los diferentes géneros musicales, pues la gama es bastante amplia. La música está también asociada al ritual y ha sido un elemento de conexión con lo espiritual y lo divino. Permite entrar en trance sin la ayuda de otras sustancias y ofrece un lenguaje de resistencia frente a la discriminación y la esclavitud, como lo ha sido por ejemplo la música Gospel del sur de los Estados Unidos, o como ha sido el Hip-hop, y el break dance, que comenzaron como una expresión de resistencia en las prisiones entre los miembros de las pandillas afro en ese mismo país.

\section{El Teatro}

Desde la antigua Grecia nos llegan las representaciones en vivo de enormes tragedias y del drama de la guerra. Antígonas furiosas desafiando la ley para poder enterrar a sus muertos, rasgando vestiduras, haciendo brotar sangre con las uñas, untándose de ceniza el cuerpo, llorando la enormidad de tragedias que solo han dejado regueros de muertos. Muchas puestas en escena pueden ser consideradas como formas de teatro. Al buscar el origen de la palabra teatro aparecen varias etimologías, como el "lugar para contemplar" el escenario, el lugar donde los actores representan dramas, historias, comedias, frente a un público, donde puede haber acompañamiento de música, sonidos, escenografias, gestos, palabras y muchos otros elementos.

La proliferación de violencia como entretenimiento y el teatro del horror y la crueldad que vemos a diario en los noticieros es el otro lado del espectáculo. La representación de la violencia y la violencia de la representación nos debe interesar de varias maneras. Vale la pena preguntarse cuál ha sido el uso de mostrar escenas de violación, asesinato, venganzas brutales y otros actos espantosos que han habitado los escenarios desde la antigüedad. La pregunta es hasta qué punto todo esto es gratuito y melodramático y cuándo cumple un 
propósito especifico. Hasta qué punto esta violencia está alimentando el apetito por más violencia, o cuando nos enseña y nos hace ver las injusticias y llorar y lamentar los errores cometidos. Veamos algunos ejemplos.

\section{El Teatro Invisible}

Este es también una rama de lo que se ha llamado teatro de los oprimidos. Se originó en Latinoamérica como una forma de protesta política, con el fin de llegar de maneras diferentes a la comunidad. Este es un teatro público, por lo general al aire libre, donde se involucra a los participantes en la acción y la trama, sin que ellos en un comienzo se den cuenta. Esta propuesta ha sido muy exitosa para trabajar con habitantes de la calle y prostitutas en programas ambulantes de prevención del VIH en países con altos índices de violencia como Sur África.

Otras iniciativas del teatro incluyen lo que se ha llamado role-play, o la interpretación de un rol particular, la improvisación u otras puestas en escena con el fin de sanar, de identificar problemas, de manejar la victimización y de resolver conflictos, entre otras cosas, con un claro propósito psicoterapéutico, o con un fin pedagógico. Está el teatro de imágenes, donde los participantes construyen imágenes y reflejan sus vidas, sentimientos y experiencias utilizando comunicación no verbal para revelar cosas sobre ellos mismos o sobre la familia o la sociedad que los rodea. En este grupo también se encuentra el Play Back Theater $^{6}$, una forma de improvisación en la que personas o grupos de la audiencia cuentan sus historias y ven inmediatamente como un grupo de actores las ponen en escena en frente de ellos. Es decir que se logra un efecto de catarsis al lograr sacar el drama de las personas y representarlo con posibles soluciones. Similar a este, encontramos otro tipo de teatro donde se crea un proceso en el cual los participantes crean personajes con sus vidas, sentimientos o experiencias.

6 En el siguiente enlace se encuentran algunas de las actividades de esta organización dedicadas a combatir el matoneo en las escuelas en muchos paises: http://www.playbacktheatre.org/ 


\section{Agitprop}

Este término significa literalmente la unión de las palabras agitación y propaganda. Se comienza a utilizar dentro de las nuevas formas de protesta creativa tomando elementos tradicionales del teatro, en temas como el medio ambiente y el calentamiento global, desigualdad social y dentro de los movimientos sociales por los derechos humanos y la paz, como lo que ha hecho el grupo Mujeres de negro por la paz ${ }^{7}$.

Aunque los anteriores tipos de teatro se han trabajado principalmente con personas adultas, hay formas específicas empleadas dentro de la población infantil. Por ejemplo los muñecos y los títeres ya se usan de manera rutinaria para entrevistar niños en casos donde hay sospecha de maltrato o abuso sexual, o para recoger evidencias o testimonios. El arte de los títeres es tan antiguo como la humanidad. Sus posibilidades como generador de comunicación, el humor que permite develar inquietudes y la confluencia de las diversas artes en el teatro de títeres, lo convirtieron en un vehículo propicio para acompañar distintas situaciones. Genera dialogo, conocimiento, alegría y capacidad de expresarse. A lo largo de la historia el títere ha sido contestatario, rebelde y divertido. Su esencia popular le ha permitido transitar diferentes rumbos del arte.

En cuanto al arte como herramienta de educación para la no-violencia, se propone que sea parte integral del currículo escolar, como una presencia permanente en el salón de clase; que sea esta una experiencia personal transformadora que pueda abrir espacios de no violencia que resulten en reproducción de conocimientos y de ser posible, convertirse en espacios de subsistencia económica. Pues no se debe dejar de tener en cuenta que la violencia también está relacionada con el sufrimiento humano resultante de la pobreza y de las desigualdades sociales que deben tratar de aliviarse si se quiere construir una mejor sociedad. Por eso dentro de las propuestas de estrategias para la paz que deben ir de la mano con las artes creativas para prevenir y resolver conflictos sociales y politicos, se debe tener

\footnotetext{
Para mayor informacion sobre esta organización y sus actividades se puede encontrar informacion en los siguientes enlaces: https://coeducando.wordpress.com/tag/mujeres-de-negro/ y http:// mujeresdenegromadrid.blogspot.com/
} 
en cuenta el desarrollo comunitario junto con la necesidad de construir nuevos símbolos.

Obviamente que cuando se trabaja el arte y la violencia hay que tener muy claro de qué clase de violencia se está hablando. ¿Se trata de la violencia de la pobreza urbana diaria, de la casa, el colegio, el vecindario, el país? Todas juntas están interconectadas, se alimentan y se reflejan unas a otras.

En conclusión, el propósito de este ensayo fue el de abrir la discusión y sugerir otras formas de pensar el tema de violencia y construcción de paz desde otro punto de vista y repensando modelos tradicionales de análisis, desde el actuar en el mundo real y en el mundo imaginado por el arte, desde una puesta en escena diferente. El arte puede ser un elemento crucial en la reparación de las comunidades crónicamente afectadas por la violencia. A través del teatro y de otras expresiones artísticas podemos tomar distancia, interpretar otros personajes y vernos de maneras diferentes; podemos visibilizar y actuar las historias que solo oímos en voz baja. También es posible incluir, participar, comunicar y transformar.

Después de este breve recuento y caracterización de las posibilidades ofrecidas por el arte, quedan todo un mundo por explorar desde la perspectiva de las nuevas tecnologías de video y de voz que permiten variadas y alternativas formas de comunicación y de transformación social, de repensarnos y de avanzar en la creación de una nueva sociedad. Los medios de comunicación y las redes sociales ya comienzan a sentir el poder de cambio que pueden tener, es esta una tarea enorme que queda por explorar.

\section{Referencias}

Babcock, B. (1984). Arrange into disorder: Fragments and reflections into Ritual Clowning. En MacAloon, J. (Ed.). Rite, drama, festival, spectacle, rehearsals: Toward a theory of cultural performance (pp. 297-308). Philadelphia: Institute of the Study of Human Issues. 
Bickhart, R. y Benn, R. (2004). Dissenting views: Art in the Age of Terror. En Peace Calendar of the War Resisters League. New York: War Resisters League.

Blasco-Ibañez, V. (1893). La cencerrada y otros cuentos. Kindle Editions. Amazon.com

Da Matta, R. (2002). Carnavales, malandros y héroes: Hacia una sociología del dilema brasileño. México: Fondo de Cultura Económica.

Lederach, J. P. (2008). La imaginación moral, el arte y el alma de construir la paz. Bogotá: Editorial Norma.

Sontag, S. (1990). On Photography. New York: Knopf Doubleday.

Goffman, E. (1993). La presentación de la persona en la vida cotidiana. Buenos Aires: Amorrortu.

Turner, V. (1987). Carnival, ritual, and play in Rio de Janeiro. En Falassi, A. Time out of time: Essays on the festival (pp. 74-90). Albuquerque: University of New Mexico Press.

Turner, V. (1988). El Proceso Ritual Estructura y Antiestructura. Madrid: Taurus Alfaguara.

Turner, V. (1990). La selva de simbolos. Madrid: Siglo XXI.

Van Gennep, A. (1960). The rites of passage. Chicago: University of Chicago Press William, S. (2001). The usefulness of humor. En Reychler, L. y T. Paffenholz. Peace-building: A field guide. London: Lynne Rienner Publishers.

\section{Cómo citar este artículo}

Tovar P. (2015). Una reflexión sobre la violencia y la construcción de paz desde el teatro y el arte. Universitas Humanística, 80, 347-369. http://dx.doi. org/10.11144/Javeriana.UH80.rvcp 